\title{
Dynamic manoeuvres on MRI in oral cancers - A pictorial essay
}

\section{Diva Shah}

HCG Cancer Centre, Sola Science City Road, Ahmedabad, Gujarat, India

Correspondence: Dr. Diva Shah, HCG Cancer Centre, Sola Science City Road, Ahmedabad - 380060, Gujarat, India. E-mail:drdiva1923@yahoo.co.in

\begin{abstract}
Magnetic resonance imaging has been shown to be a useful tool in the evaluation of oral malignancies because of direct visualization of lesions due to high soft tissue contrast and multiplanar capability. However, small oral cavity tumours pose an imaging challenge due to apposed mucosal surfaces of oral cavity, metallic denture artefacts and submucosal fibrosis. The purpose of this pictorial essay is to show the benefits of pre and post contrast MRI sequences using various dynamic manoeuvres that serve as key sequences in the evaluation of various small oral (buccal mucosa and tongue as well as hard/soft palate) lesions for studying their extent as well as their true anatomic relationship.
\end{abstract}

Key words: Dynamic manoeuvres; MRI; oral cavity lesions

\section{Introduction}

In the imaging of oral cavity lesions, it is important to determine precisely the site of tumour origin, size, trans-spatial extension and invasion of deep structures. ${ }^{[1]}$ Evaluation of small tumours of the oral cavity is always a diagnostic challenge for both the head and neck surgeon and the head and neck radiologist.

Small gingivo-buccal, retromolar trigone (RMT) or small tongue lesions are routinely obscured on cross sectional imaging by close apposition of mucosal surfaces of lips and cheeks to the gingival surfaces of alveolar processes or apposition of the tongue to the lingual surfaces of alveolar processes and the hard palate. ${ }^{[2]}$

Dynamic manoeuvres on multidetector CT(MDCT) imaging of oral cavity lesions are well known an established technique..$^{[1-7]}$ However, MDCT remains suboptimal in the evaluation of small

\begin{tabular}{|l|l|}
\hline \multicolumn{2}{|c|}{ Access this article online } \\
\hline Quick Response Code: & \\
\cline { 1 - 2 } & Website: \\
& www.ijri.org \\
& DOI: \\
\hline
\end{tabular}

oral cavity lesions particularly in patients with sub-mucosal fibrosis, RMT lesions, post-operative evaluation and in presence of metallic dental streak artefacts. MRI in these circumstances scores over MDCT and is a preferred modality with excellent soft tissue contrast resolution.

MR imaging with various dynamic manoeuvres provides precise imaging information about the location of small inconspicuous lesions in the oral cavity - their exact site of origin and the extent of the larger or exophytic tumours. ${ }^{[8]}$ Use of dynamic manoeuvres in MRI helps either 'rule in' small lesions or 'rule out' tumour extension.

\section{Learning Objectives}

- To demonstrate usefulness of various dynamic manoeuvres in pre and post-contrast MRI sequences

This is an open access journal, and articles are distributed under the terms of the Creative Commons Attribution-NonCommercial-ShareAlike 4.0 License, which allows others to remix, tweak, and build upon the work non-commercially, as long as appropriate credit is given and the new creations are licensed under the identical terms.

For reprints contact: WKHLRPMedknow_reprints@wolterskluwer.com

Cite this article as: Shah D. Dynamic manoeuvres on MRI in oral cancers - A pictorial essay. Indian J Radiol Imaging 2020;30:334-9.

Received: $27-F e b-2020$

Accepted: 24-Jul-2020

Revised: 08-Apr-2020 Published: $15-$ Oct-2020 
for the evaluation small buccal mucosa/alveolar mucosa lesions

- To demonstrate true anatomic relationships of small oral cavity lesions arising from tongue, hard/soft palate, and floor mouth lesions

- To compare with conventional MR sequences for evaluation of oral cavity lesions.

\section{Normal Anatomy}

The oral cavity is divided into a central part "oral cavity proper" and "vestibule". The oral cavity proper is bounded by the alveolar arches and communicates posteriorly with the oropharynx. Its roof is formed by hard palate and floor by mucosa of floor of mouth. The anterior two-third of the tongue also known as mobile tongue is contained within oral cavity proper. ${ }^{[2]}$ The vestibule is lined by the buccal mucosa laterally, superiorly and inferiorly by reflections of the buccal mucosa onto the mandible and maxilla respectively, referred as the upper and lower gingivobuccal sulci (GBS) and the gingival mucosa medially. ${ }^{[3]}$ The buccal space or bucco-masseteric space lies lateral to the vestibule.

At rest, the buccal mucosa, gingival mucosa, mucosa lining the inner surface of lips and vestibular reflections remain apposed to each other. Superior and inferior GBS remain apposed with gingiva..$^{[8]} \mathrm{RMT}$ is a triangular shape mucosal fold that extends behind the last molar teeth of mandible up to the maxillary last molar teeth on either side. Pterygomandibular raphe lies behind the RMT and attaches superiorly to pterygoid hamulus and inferiorly posterior border of mylohyoid muscle. ${ }^{[2,3,8]}$

\section{Dynamic Manoeuvres}

The purpose of radiological interpretation is to portray meaningful information to clinical colleagues. Below described the useful dynamic manoeuvres that act as key sequences for evaluation of small or hidden oral cavity lesions [Table 1]. The optimal MRI sequences for each manoeuvres and its MRI parameters are mentioned below [Table 2].

\section{Manoeuvre 1: Puffed Cheek Manoeuvre}

\section{Technique}

Puffed cheek MRI manoeuvre is performed by asking the patient to blow the mouth uniformly through pursed lips. This technique can be optimized by asking the patient to move the tongue away from the hard palate and the teeth.

By puffing the cheeks, the oral vestibule is filled with air, which by creating a negative contrast, separates the buccal and labial mucosa from the gingival mucosa, allowing both mucosal surfaces to be assessed separately ${ }^{[1]}$ [Figure 1]. This manoeuvre can be easily adopted by the patient and adds negligible amount of time on total scan time. The buccinator muscle is better seen on puffed-cheek images [Figure 1] than on the conventional MRI scans, ${ }^{[5,6]}$ thus helping either "rule in" or "rule out" tumour extensions and the depth of muscle invasion.

\section{Advantage}

It is helpful in evaluation of small primary buccal mucosa lesion involving anterior buccal mucosa, anterior part of upper or lower GBS and angle mouth/vestibule. Strong metallic artefacts caused by dental implants and metallic orthodontic appliances are a common problem in head and

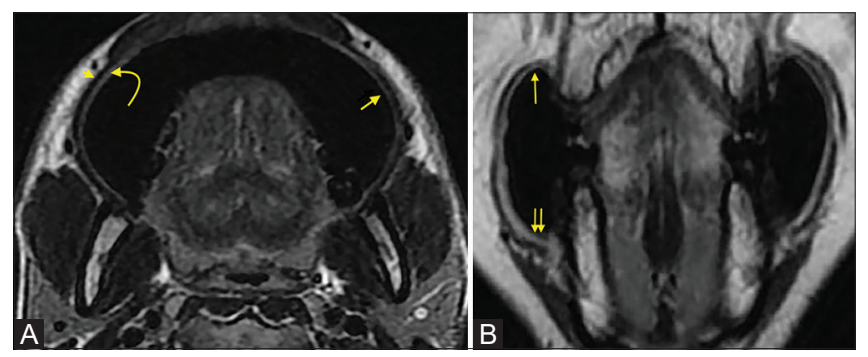

Figure 1 (A and B): Puff cheek manoeuvre. (A) - axial - T2W MRI image depicts normal MR anatomy of oral vestibule showing normal buccal mucosa (arrow), submucosa (curved arrow), buccinator muscle (small arrow). (B) - coronal T2W depicts upper and lower GB sulci (arrow and double arrow)

Table 1: Useful dynamic manoeuvres for oral cancer evaluation on MRI

\begin{tabular}{|c|c|c|}
\hline Type of manoeuvre & Tumour Location & Results \\
\hline $\begin{array}{l}\text { Puffed cheek/Water } \\
\text { distension }\end{array}$ & $\begin{array}{l}\text { Anterior buccal } \\
\text { mucosa }\end{array}$ & $\begin{array}{l}\text { Delineates origin and exact extent, depicts the angle of mouth, GBS and alveolar mucosa involvement/ } \\
\text { exclusion. } \\
\text { Deep extension into buccal fat pad and deep buccal fascia exclusion is more confidently evaluated. } \\
\text { Can help differentiate post-operative thickening from recurrent lesion. } \\
\text { Can help avoid/reduced artefacts from metallic dentures. }\end{array}$ \\
\hline Water distension & $\begin{array}{l}\text { RMT/Posterior } \\
\text { buccal mucosa/ } \\
\text { Alveolus }\end{array}$ & $\begin{array}{l}\text { True involvement of RMT with deeper extent into pterygomandibular raphe and relationship with medial pterygoid muscle } \\
\text { can be more confidently evaluated. }\end{array}$ \\
\hline $\begin{array}{l}\text { Tongue Protrusion } \\
\text { and Water distension }\end{array}$ & Tongue & $\begin{array}{l}\text { Helps in evaluation of ventrolateral marginal lesions, excludes extension in floor of mouth particularly for ventral surface } \\
\text { lesions, and helps better evaluation of depth of invasion exophytic (proliferative) tongue lesions } \\
\text { Evaluates tip of tongue lesions more precisely, especially following post neo-adjuvant chemotherapy response } \\
\text { evaluation. }\end{array}$ \\
\hline Open mouth & Palate & Extent and involvement of hard palate mucosa and extension along upper alveolar mucosa and soft palate . \\
\hline
\end{tabular}


neck MRI. ${ }^{[6]}$ This manoeuvre is used to improve detection and correct staging of small lesions in the oral cavity whenever artefacts are present [Figure 2]. Also, it helps to delineate the extent, mucosal and sub-mucosal spread [Figure 3], buccinator involvement and rule out/rule in outer gingival or alveolar mucosal involvement. ${ }^{[9,10]}$ Precise evaluation of location, extent and anatomic relationship of the oral cavity lesions helps the surgeon in planning of primary surgery and type of reconstruction for minimizing morbidity.

\section{Limitation}

This manoeuvre has limitations in patients with severe sub-mucosal fibrosis, evaluation of posterior GBS and RMT lesions and in post-operative patients with large flap reconstruction for oral cancers which does not allow proper distension of oral cavity.

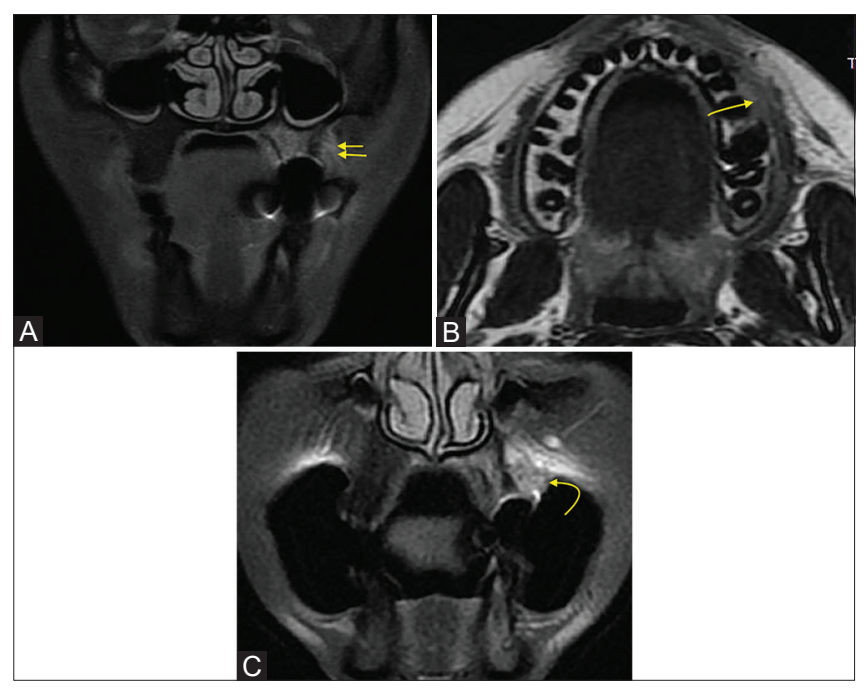

Figure 2 (A-C): Salivary Gland Tumor (Mammary Analogue Secretary Carcinoma). (A) Coronal T2W and (B) Axial T2WFS images show ill-defined thickening in left anterior upper gingivo-buccal space (arrow and double arrows) with metallic denture artifacts in left upper alveolus. (C) Coronal T1W FS post contrast image with puff cheek manoeuvre shows a focal enhancing lesion in left anterior upper GB sulcus with abnormal marrow signal in left upper alveolus (curved arrow), Resolution of metallic denture artifact due to distension of oral cavity

\section{Manoeuvre 2: Water Distension of Oral Vestibule}

\section{Technique}

This manoeuvre is performed by distension of oral vestibule by asking patient to drink 20-40 cc of plain water and hold it in mouth, patients have good compliance to hold water in mouth for 80 seconds only during pre and post contrast T2W and T1WFS sequences. This manoeuvre aids by providing an excellent natural contrast between lesion and adjacent normal buccal mucosa and other anatomic structures on T2W and post contrast T1W FS (fat saturated) MRI sequences. The pterygomandibular raphe and RMT

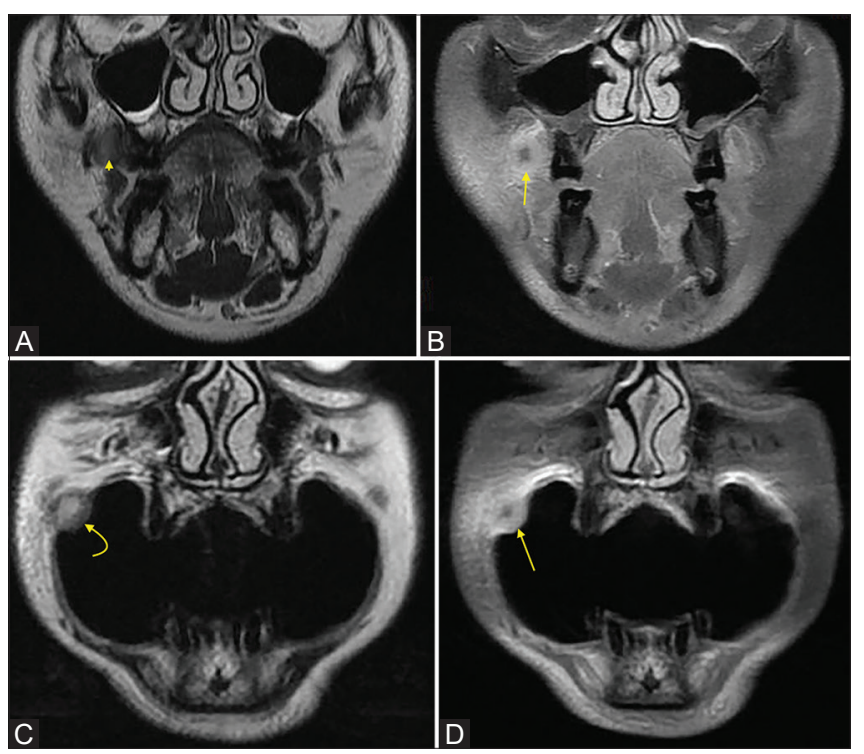

Figure 3 (A-D): Minor salivary gland tumor -Mucoepidermoid carcinoma from minor salivary gland rests near parotid duct opening. (A and B) Coronal T2W and T1 FS post contrast image shows poorly defined nodule in right upper GB sulcus region (arrow). (C) Coronal T2W and (D) post contrast T1WFS images with puff cheek manuvers show a well-defined peripheral rim enhancing submucosal nodule (curved and straight arrow) opposite to right upper $2^{\text {nd }}$ molar teeth, upper GB sulcus is free, parotid duct opening not seen

Table 2: Optimal MRI sequences for each manoeuvres in oral cancer evaluation

\begin{tabular}{|c|c|c|c|c|}
\hline MRI Sequences for dynamic Manoeuvre & Number of slices & Slice thickness $(\mathrm{mm})$ & Inter Slice gap (mm) & Sequence time duration (sec) \\
\hline \multicolumn{5}{|l|}{ Puffed Cheek Manoeuvre } \\
\hline $\mathrm{T} 2 \mathrm{~W}$ coronal or $\mathrm{T} 2 \mathrm{~W}$ axial & $16-20$ & $3-4$ & $0.5-1$ & 80 \\
\hline $\begin{array}{l}\text { T1WFS coronal or T1WFS axial post } \\
\text { contrast }\end{array}$ & $16-20$ & $3-4$ & $0.5-1$ & 80 \\
\hline \multicolumn{5}{|l|}{ Water Distension Manoeuvre } \\
\hline T2W coronal or T2W axial & $16-20$ & $3-4$ & $0.5-1$ & 80 \\
\hline Post contrast T1WFS coronal or T1WFS axial & $16-20$ & $3-4$ & $0.5-1$ & 80 \\
\hline \multicolumn{5}{|l|}{ Tongue Protrusion Manoeuvre } \\
\hline T2/T2WFS sagittal or axial & $16-18$ & 3 & $0.5-1$ & 60 \\
\hline Post contrast T1WFS sagittal or axial & $16-18$ & 3 & $0.5-1$ & 60 \\
\hline \multicolumn{5}{|l|}{ Open Mouth Manoeuvre } \\
\hline T2 coronal or T2 sagittal & $16-20$ & $3-4$ & 1 & 60 \\
\hline Post contrast T1WFS coronal or sagittal & $16-20$ & $3-4$ & 1 & 60 \\
\hline
\end{tabular}


can be better delineated [Figure 4]. The natural contrast also delineates inner alveolar mucosa, thus help rule in/rule out alveolar mucosa involvement.

\section{Advantage}

Evaluation of small posterior buccal mucosa/RMT tumours and its deeper extent is a real challenge to radiologist. The manoeuvre can optimally distend the oral vestibule. As water retains in RMT region in dependent position during MRI study, it helps in distension of posterior (dependent) aspect upper and lower GBS and RMT that are not well evaluated with puffed cheek technique or on CT scan [Figure 5].

The author recommends water distension technique particularly in evaluation of patients with severe sub-mucosal fibrosis, lesion sitting in RMT and lesions of posterior buccoalveolar mucosa [Figure 6] where smaller mucosal lesions can be missed during clinical examinations or exact depth and extent cannot be evaluated during clinical examination/CT scan/conventional MRI scan. This manoeuvre has added value for chronic tobacco chewer with significant submucosal fibrosis which hinders evaluation of oral cavity either clinically or on conventional CT scan, and also on MRI [Figure 7].
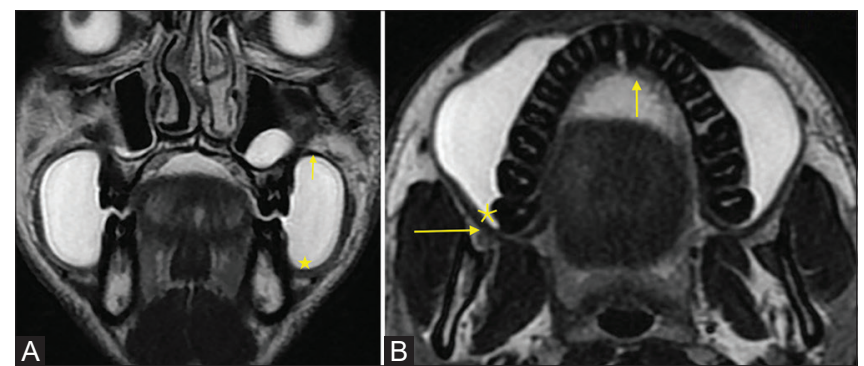

Figure 4 (A-E): Water Distension Manoeuvre (A and B) (A) Distension of oral vestibule with water on coronal T2W image shows upper and lower GB sulci (straight arrow and asterisk). (B) axial T2W images shows distension of RMT (asterisk), Caudal aspect of pterygomandibular raphe (arrow) and visualization of inner alveolar mucosa (arrow)

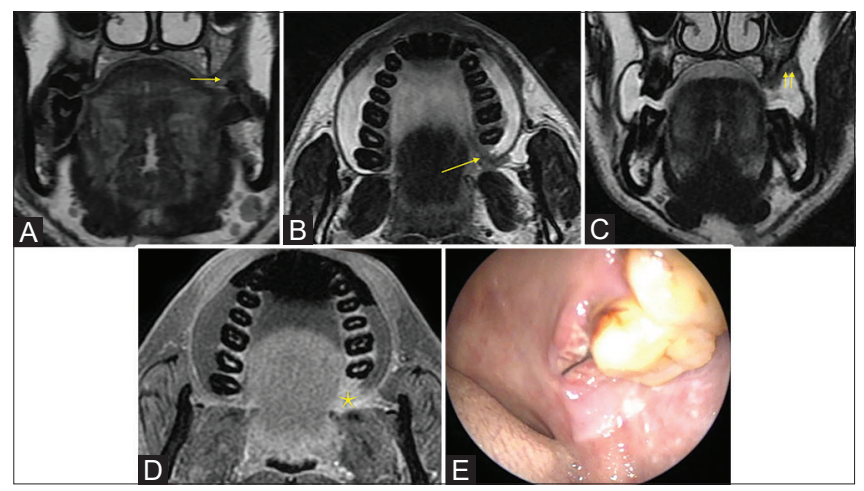

Figure 6 (A-E): Well differentiated SCC of left RMT. (A) Coronal T2W image at the level of RMT and posterior buccal mucosa shows minimal ill-defined thickening (arrow). (B) axial, (C) coronal T2W and (D) axial post contrast T1W FS images with water distension show an irregular lesion of posterior upper GB sulcus and RMT with extension into inferior aspect of pterygomandibular raphe, (Arrow, double arrow and asterisk) (E) Clinical picture of RMT lesion
Post-operative oral cavity lesions are a real challenge to onco-radiologists particularly to demonstrate small recurrent malignant lesions of buccal mucosa. Due to post-operative fibrosis, these patients cannot perform puffed cheek manoeuvre. In such scenarios, water distension manoeuvre helps to distend the oral vestibule [Figure 8].

MRI is a reliable tool in assessing the depth of invasion and thickness of tumours of tongue and has a significant correlation with the final histopathological findings. ${ }^{[11,12]}$ However, in certain exophytic lesions, conventional MRI has

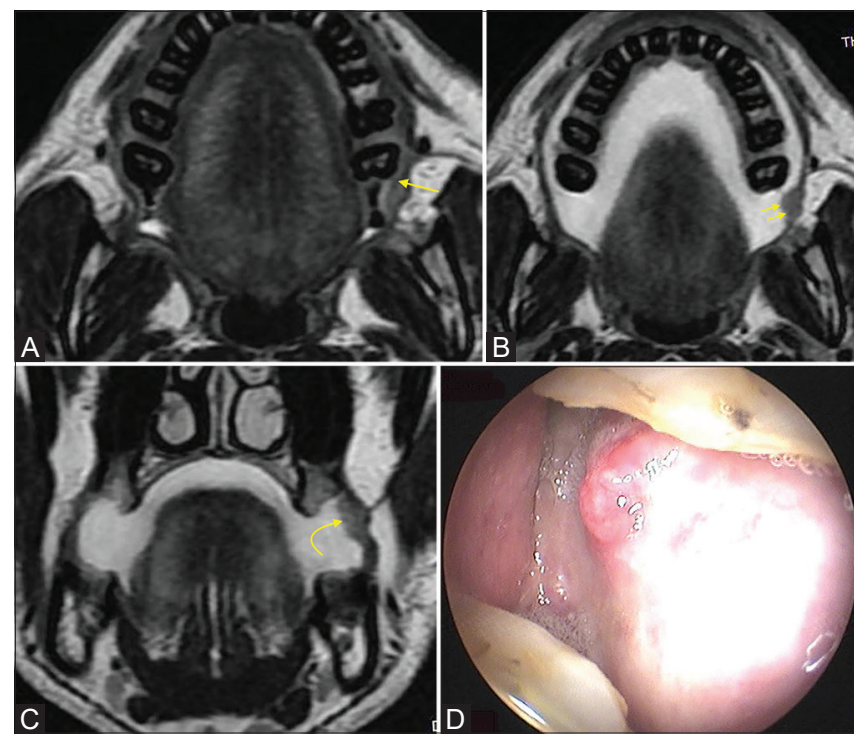

Figure 5 (A-D): Left posterior buccal Mucosa Ulcer with severe Sub-mucosal Fibrosis. (A) Axial T2W image shows ill-defined thickening in left posterior buccal mucosa (arrow), (B) axial and (C) coronal T2W images with water distension manoeuvre clearly show a small lesion involving left posterior upper buccal mucosa, minimally bulging in deep buccal fat pad (Double and curved arrow). (D) clinical picture of small ulcerative lesion

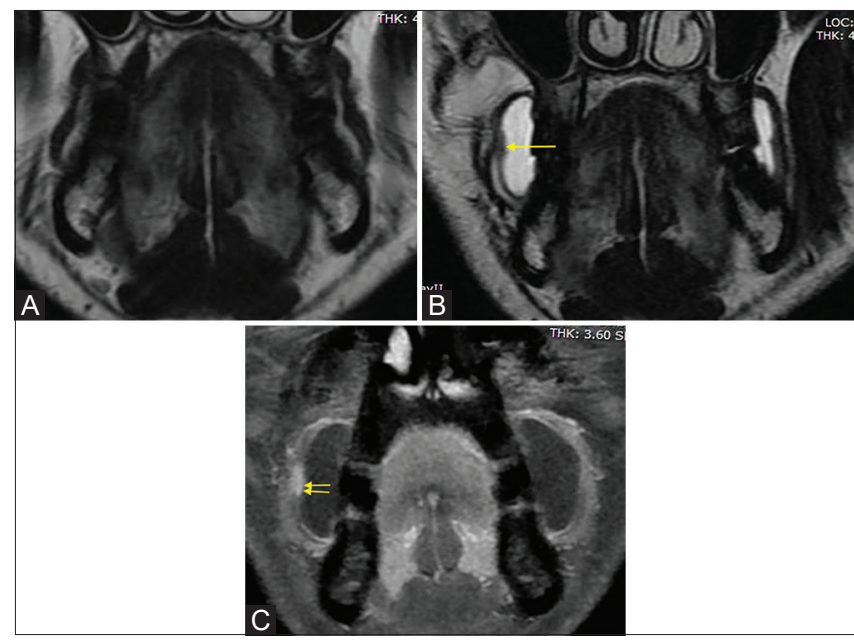

Figure $7(\mathbf{A}-\mathbf{C})$ : Chronic Tobacco Chewer with Sub-mucosa Fibrosis. (A) coronal T2W image shows no abnormality. (B) coronal T2W and (C) Post contrast T1W FS images show small enhancing thickening involving mucosa and submucosa (arrow and double arrow), Biopsy revealed severe dysplasia with squamous cell carcinoma in situ 
limitations in assessing depth of tumour invasion and tumour thickness. Water distension manoeuvre helps in evaluation of exophytic tongue lesions, delineates true exophytic and intra-substance infiltrative component [Figure 9].

\section{Limitation}

Water distension of vestibule cannot be performed in patients with oro-cutaneous fistula, edentulous patients and in post-operative oral cavity with large flap reconstruction. This manoeuvre does not give any additional information for large buccal mucosa or other large oral cavity lesions because for such lesions locoregional extension and relationship with adjacent neck spaces are more relevant.

\section{Manoeuvre 3: Tongue Protrusion Manoeuvre}

MRI with contrast is the choice of modality for evaluation of tongue lesions and its extent. Small tongue lesions along the

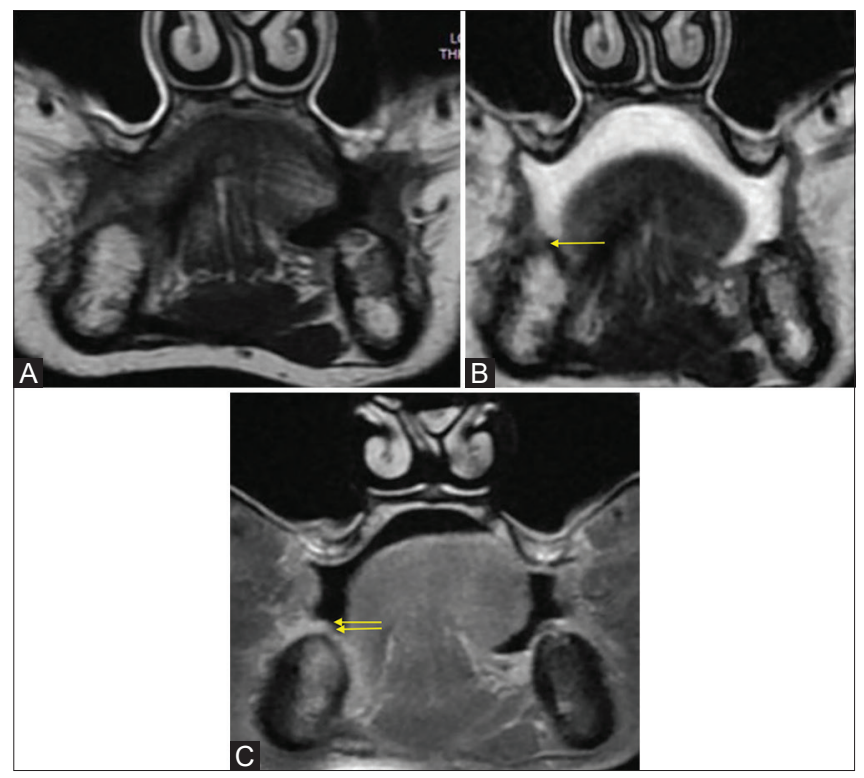

Figure 8 (A-C): Operated left lateral margin of tongue. (A) T2W coronal image shows post-operative changes along left lateral margin of tongue. (B and C) T2W and T1WFS coronal images with water distension and open mouth show irregular enhancing mucosal thickening (arrow and double arrow) in right lower GB sulcus, biopsy showed invasive SCC

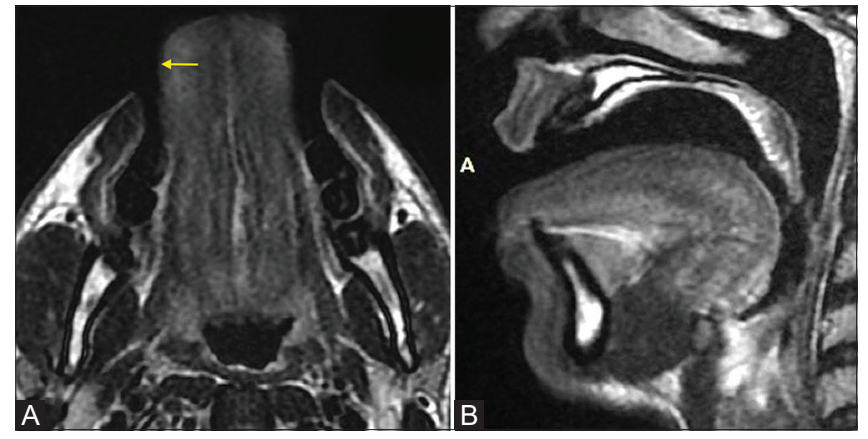

Figure 10 (A and $B$ ): Tongue protrusion manoeuvre (A) T2W axial and $(B)$ sagittal images show protruded anterior aspect of tongue lateral and ventral surface of tongue are difficult to assess due to close apposition of soft tissue at rest and artefacts generated by dental amalgams. ${ }^{[8]}$

\section{Technique}

This manoeuvre is performed by asking the patient to protrude the tongue against floor of mouth as much as possible and sequence acquired while the patient protrudes the tongue [Figure 10].

\section{Advantage}

This is a useful additional manoeuvre along with conventional MRI sequences for small tongue lesion along lateral and ventral aspect of anterior oral tongue or lesion involving tip (apex) of tongue [Figure 11].

\section{Limitation}

Manoeuvre does not give any additional information for large tongue lesions or lesions of isolated floor of mouth/base of tongue. Motion artifacts are common while performing this manoeuvre.

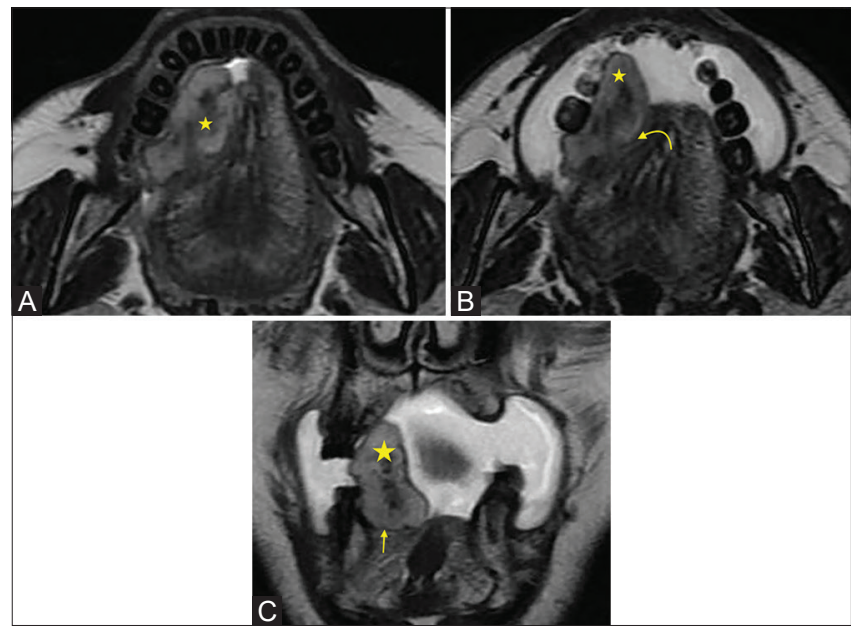

Figure 9 (A-C): WDSCC of right lateral aspect of tongue. (A) Axial $\mathrm{T} 2 \mathrm{~W}$ image shows an irregular lesion from right antero-lateral aspect of tongue, abutting adjacent genioglossus muscle. ( $\mathrm{B}$ and $\mathrm{C}$ ) axial and coronal T2W images after water distension of vestibule shows an irregular large exophytic lesion (Asterisk) with minimal intra-substance infiltrative component (arrow and curved arrow )
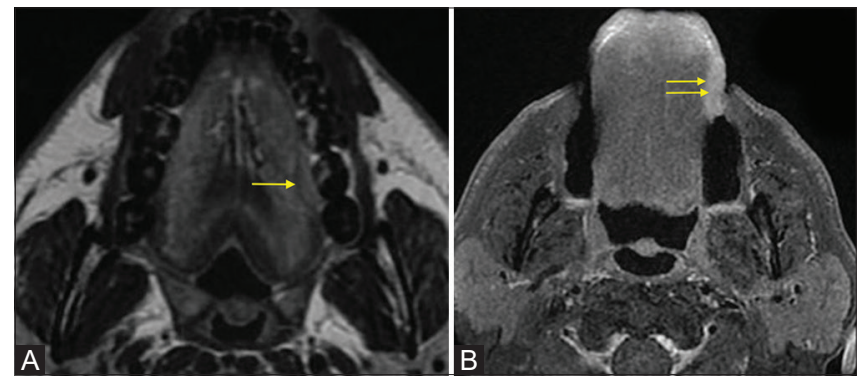

Figure 11 (A and B): MDSCC of left lateral and ventral aspect tongue. (A) Axial T2W images show subtle intermediate signal intensity along left lateral aspect of tongue (arrow). (B) Post contrast T1WFS image with protrusion of tongue show enhancing lesion along the left ventrolateral margin.(Double arrow) 

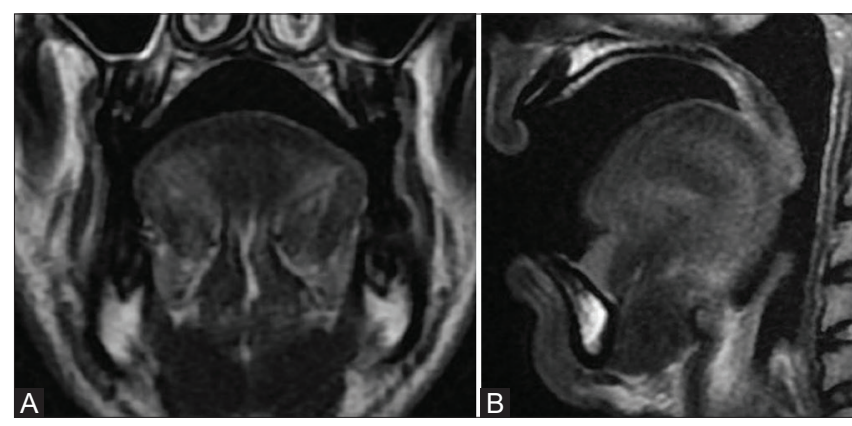

Figure 12 (A and B): Open mouth manoeuvre. (A) T2W coronal and (B) sagittal images with open mouth manuvers

\section{Manoeuvre 4 Open Mouth Manoeuvre}

\section{Technique}

The open mouth manoeuvre is performed by asking the patient to hold in open mouth position during MRI sequence [Figure 12]. A device (syringe) can be placed between teeth to ensure proper immobilization. The open mouth technique is also helpful when lesion of the oropharynx is not clearly visible because of dental amalgam artefact. ${ }^{[3]}$

\section{Advantage}

It is a useful manoeuvre for evaluation of small lesions of hard palate or and soft palate mucosa ${ }^{[9]}$ [Figure 13]. It helps to delineate precise thickness of the lesion, presence and involvement of extent of upper alveolar mucosa, RMT and adjacent GB sulcus easily or secondary involvement of palate in primary upper alveolar lesions. Delineate exact extent of palatal lesions which helps in oncoplastic reconstructions of palatal defects.

\section{Limitation}

Motion artifact is a major limitation of this manoeuvre.

\section{Conclusion}

Dynamic manoeuvres are simple and easy with short duration MR sequences as they overcome the limitations of MDCT scan and MRI and thus provide more detailed and specific information to the surgical oncologist for delineating exact margins and better oncoplastic reconstruction in the era of minimal invasive surgery. The use of dynamic manoeuvres in MRI helps either 'rule in' small lesions or 'rule out' tumour extensions in lesions of oral cavity. Such manoeuvres should always be incorporated in routine clinical MRI practice for evaluation of oral cavity lesions by the radiologist.

\section{Financial support and sponsorship}

Nil.

\section{Conflicts of interest}

There are no conflicts of interest.

\section{References}

1. Celebi I, Oz A, Sasani M, Bayindir P, Sözen E, Vural C, Başak M. Using dynamic manoeuvres in the computed tomography/magnetic

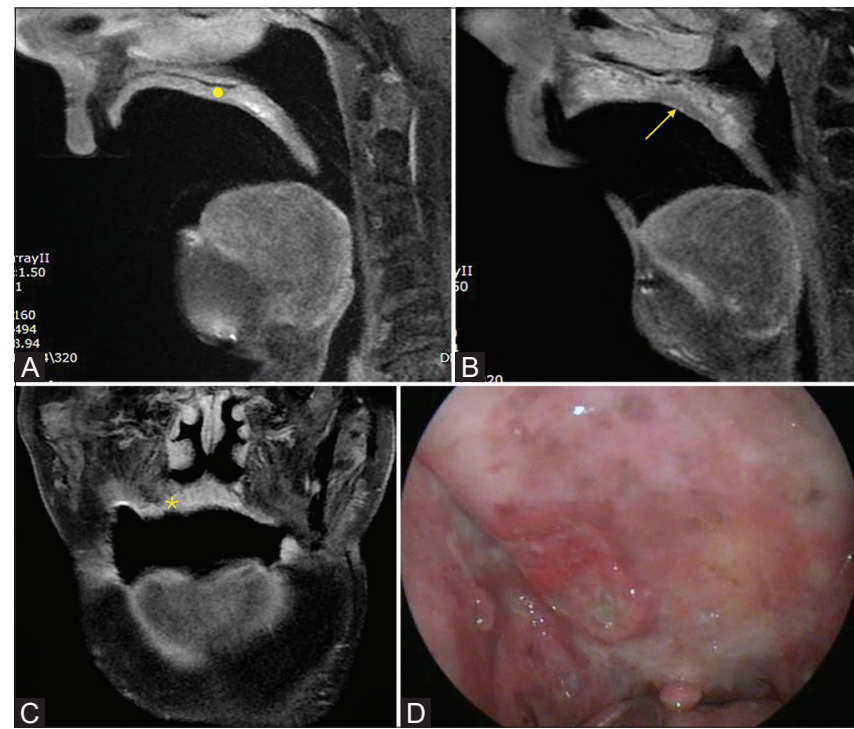

Figure $13(A-D)$ : Malignant Ulcer in palate in an operated carcinoma of central Arch Alveolus. (A) sagittal T1WFS images with open mouth shows a normal mucosa on left side of hard and soft palate (circle). (B) Sagittal and (C) coronal post-contrast T1FS show irregular enhancing lesion involving posterior aspect of hard palate and junction of soft palate, also involving adjacent right upper alveolar mucosa (arrow and asterisks) (D) shows the clinical picture of ulcerative lesion in palate

resonance assessment of lesions of the head and neck. Can Assoc Radiol J 2013;64:351-7.

2. Fatterpekar GM, Delman BN, Shroff MM, Naidich TP, Sacher MS, Som PM. Distension technique to improve computed tomographic evaluation of oral cavity lesions. Arch Otolaryngol Head Neck Surg 2003;129:229-32.

3. Arya S, Chaukar D, Pai P. Imaging in oral cancers. Indian J Radiol Imaging 2012;22:195-208.

4. Kim HC, Moon MH, Han MH, Kim JH, Kim IO, Chang KH $\mathrm{CT}$ and MR imaging of the buccal space: Normal anatomy and abnormalities. Korean J Radiol 2005;6:22-30.

5. Weissman JL, Carrau RL. Puffed-cheek" CT improves evaluation of the oral cavity. Am J Neuroradiol 2001;22:741-4.

6. Lemos M, Gomes RLE, Zuppani HB, Silva CJ, Gebrim EMM, Garcia MRT. Sao Paulo/BR; São Paulo, SP/BR. The role of imaging in the diagnosis and staging of oral cavity cancer. Educational Exhibit ECR. 2018

7. Dillon JK, Glastonbury CM, Janeen F, Schmidt BL, Gauze padding: A simple technique to delineate small oral cavity tumors. Am J Neuroradiol 2011;32:934-7.

8. Oberoi R, Jena A. Usefulness of dynamic manoeuvres in MR evaluation of oral malignancies. Indian J Radiol Imaging 2006;16:379-84.

9. Henrot P, Blum A, Toussaint B, Troufleau P. Dynamic manoeuvres in local staging of head and neck malignancies with current imaging techniques: Principles and clinical applications Radiographics 2003;23:1201-13.

10. Paul P, Sable N, Arya S. Imaging of Oral Cancer. In: Panta P.(eds) Oral Cancer Detection. Springer Nature; 2019. p. 109-131.

11. LamP, Au-Yeung KM, Cheng PW, Wei WI, Yuen AP, Trendell-SmithN, et al. Correlating MRI and histologic tumour thickness in the assessment of oral tongue cancer. Am J Roentgenol 2004;182:803-8.

12. Weimar EAM, Huang SH, Lu L, O'Sullivan B, Perez-Ordonex B, et al. Radiologic-pathologic correlation of tumour thickness and its prognostic importance in squamous cell carcinoma of the oral cavity: Implication for the eight edition tumor, node, metastasis classification. AJNR Am J Neuroradiol 2018;39:1896-902. 